\title{
Association of serum magnesium level with microalbumin in urine of newly detected type-2 diabetes mellitus
}

\author{
T Nasreen ${ }^{1}$, S Ferdousi ${ }^{2}$, K Alam ${ }^{3}$, T Sultana ${ }^{4}$, T F Dipta ${ }^{5}$, S Selim ${ }^{6}$
}

Abstract

Background : Magnesium $(\mathrm{Mg}++)$ deficiency is associated with poor glycemic control and $\mathrm{Mg}++$ supplementation lowers blood sugar, improves insulin sensitivity and delays diabetic complications such as diabetic nephropathy, diabetic neuropathy, diabetic retinopathy.

Objective : This study was designed to know the status of serum $\mathrm{Mg}++$ in type 2 diabetic subjects with microalbuminuria and normoalbuminuria.

${ }^{1}$ Dr. Tania Nasreen Medical Officer

Transfusion Medicine and Clinical Haematology Dept. BIRDEM General Hospital, Dhaka

${ }^{2}$ Dr. Sheuly Ferdousi

Assistant Professor

Dept. of Laboratory Medicine

Bangabandhu Sheikh Mujib

Medical University

(BSMMU), Dhaka

${ }^{3}$ Dr. Khorshed Alam

Assistant Professor

Dept. of Pathology

Bashundhara Ad-din Medical

College and hospital, Dhaka

${ }^{4}$ Prof. Tuhin Sultana

Professor

Dept. of Laboratory Medicine

BSMMU, Dhaka

${ }^{5}$ Prof. Tashmim Farhana Dipta

Professor and Head

Transfusion Medicine and

Clinical Haematology Dept.

BIRDEM General Hospital, Dhaka

${ }^{6}$ Dr. Shahjada Selim

Assistant Professor

Dept. of Endocrinology

BSMMU, Dhaka

Correspondence

Dr. Tania Nasreen

Medical Officer, Transfusion

Medicine and Clinical

Haematology Department,

BIRDEM General Hospital, Dhaka

e-mail: tnshimul3@gmail.com

Methodology : This study was conducted at the Department of Laboratory Medicine (Clinical Pathology) in collaboration with BIRDEM General Hospital, Dhaka. In this study, serum magnesium level and urine microalbumin level of 120 newly detected type 2 diabetic patients were measured. Both levels were measured by biochemical auto analyzer (Siemens Dimension RL Max).

Result : The mean microalbumin level was found $22.9 \pm 3.1 \mathrm{mg} / \mathrm{L}$ with range from $2-105 \mathrm{mg} / \mathrm{L}$ and the mean magnesium level was found $1.9 \pm 0.3 \mathrm{mg} / \mathrm{dl}$ with range from $1.5-2.4 \mathrm{mg} / \mathrm{dl}$. Pearson's correlation coefficient was -0.353 between serum magnesium level and urine microalbumin which was statistically significant $(p$ value $<0.05)$. Therefore, there was a linear negative correlation between serum magnesium level and urine microalbumin.

Conclusion : The present study revealed negative correlation between serum magnesium level and urine microalbumin.

DOI: http://dx.doi.org/10.3329/nimcj.v9i2.38909

Northern International Medical College Journal Vol. 9 No. 2 January 2018, Page 291-294

Introduction

Magnesium $\left(\mathrm{Mg}^{++}\right)$is the fourth most abundant cation in the human body. ${ }^{1,2}$ One of the potential pathophysiological mechanisms linking serum magnesium to microalbuminuria is an amplification of insulin resistance. Magnesium acts as a mild, natural calcium antagonist. Therefore, the level of intracellular calcium is increased in magnesium deficiency subjects. This increased intracellular calcium may compromise the insulin responsiveness of a dipocytes and skeletal muscles which leads to the development of insulin resistance. ${ }^{2}$ Another study has also found that insulin deficiency or insulin resistance can affect the tubular absorption of magnesium, leading to hypomagnesemia in diabetic patients. ${ }^{2}$ Finally, a vicious circle formed by mutual influence between insulin resistance and hypomagnesemia which can increase the risk of microalbuminuria. ${ }^{3}$ Magnesium $\left(\mathrm{Mg}^{++}\right)$plays a key role in many fundamental biological processes including metabolism and DNA synthesis. $\mathrm{Mg}^{++}$deficiency may cause endothelial cell dysfunction, inflammation and oxidative stress. ${ }^{1}$ Endothelial cells could be injured through inflammatory response. It causes an increase in capillary permeability particularly in glomerular vessels. It induces kidneys to undergo transient proteinuria. The changes can be measured by increased levels of microalbuminuria. ${ }^{4,5}$

Insulin and glucose are important regulators of magnesium metabolism. Intracellular magnesium plays a key role in regulating insulin action, insulin-mediated-glucose-uptake and vascular tone. ${ }^{6}$ Reduced intracellular magnesium concentrations result in a defective tyrosinekinase activity, postreceptorial impairment in insulin action and worsening of insulin resistance in diabetic patients. ${ }^{2}$

Hypomagnesaemia is usually indicative of a systemic magnesium deficit. Depletion in intracellular and serum ionized magnesium can be found in many subjects with total serum magnesium still in the normal range. ${ }^{6}$ It was 
found that $25-39 \%$ of diabetics have low concentrations of serum magnesium. ${ }^{7}$ Magnesium deficit in the diet would induce insulin resistance in humans. ${ }^{2}$ If it is chronic, it may lead to macro-vascular and micro-vascular complications of diabetes. Hypomagnesaemia independently predicts the progression to end stage renal disease in patients with advanced type 2 diabetic nephropathy. ${ }^{2}$

Oxidative stress is an important causative factor for microalbuminuria. 8,9 Magnesium has antioxidant property. Hence, oxidative stress has association between low serum magnesium and microalbuminuria. ${ }^{3}$

A low magnesium intake and an increased urinary loss of magnesium appear the most important mechanisms that may favor magnesium depletion in patients with type 2 diabetes. ${ }^{1}$ $\mathrm{Mg}^{++}$intake is inversely longitudinally associated with the incidence of diabetes. ${ }^{10}$ Approximately one-third of subjects with type 2 diabetis mellitus (DM) have hypomagnesaemia mainly caused by enhanced renal excretion. Magnesium deficiency is associated with poor glycemic control and magnesium supplementation improves insulin sensitivity and delays complications. ${ }^{1,11}$

In this study,we try to find out the status of serum $\mathrm{Mg}^{++}$in type 2 diabetic subjects with microalbuminuria and normoalbuminuria.

\section{Materials and Methods}

This cross sectional study was conducted at the Department of Laboratory Medicine (Clinical Pathology) in collaboration with Department of Biochemistry and Molecular Biology, BSMMU and BIRDEM General Hospital, Dhaka. The duration of study period was from March 2016 to February 2017. Total 120 subjects of newly detected type 2 diabetes mellitus were included. Serum magnesium and urine microalbumin levels in all newly detected type 2 diabetic patients were measured. Both levels were measured by biochemical auto analyzer (Siemens Dimension RL Max). Other types of diabetes such as type- 1 diabetes, gestational diabetes etc, patients with UTI/Pyelonephritis, patients who were on magnesium based antacid medication, on long term diuretics, with malabsorption or chronic diarrhea, on dialysis were excluded. Measurement of serum concentration of magnesium and micro albumin in urine is easy and not expensive. Therefore, to know the status of serum magnesium and microalbuminuria in type 2 diabetic subjects for this study was not difficult.

\section{Result And Observations}

Total 120 subjects of newly detected type 2 diabetes mellitus were included. Serum magnesium level and urine microalbumin level were measured. After detecting the level of microalbumin in urine, patients were grouped into normoalbuminuria and microalbuminuria group. Finally correlation coefficient of magnesium and urinary microalbumin were calculated by using Pearson's correlation coefficient test.

Table I : Distribution of the study patients by serum magnesium $(n=120)$

\begin{tabular}{|c|c|c|}
\hline Serum magnesium (mg/dl) & Number of patients & Percentage \\
\hline$<1.8$ (low) & 36 & 30.0 \\
\hline $1.8-2.4$ (normal) & 84 & 70.0 \\
\hline Mean \pm SD & \multicolumn{2}{|c|}{$1.9 \pm 0.3$} \\
\hline Range (min, max) & \multicolumn{2}{|c|}{$1.5,2.4$} \\
\hline
\end{tabular}

Table I shows serum magnesium level of the study patients, it was observed that $36(30.0 \%)$ had low level $(<1.8 \mathrm{mg} / \mathrm{dl})$ and $84(70 \%)$ had normal level (1.8-2.4). The mean serum magnesium level was found $1.9 \pm 0.3 \mathrm{mg} / \mathrm{dl}$ and ranged from 1.5 to $2.4 \mathrm{mg} / \mathrm{dl}$.

Table II : Distribution of the study patients by urine microalbumin $(n=120)$

\begin{tabular}{lcc} 
Urine microalbumin(mg/L) & Number of patients & Percentage \\
Normoalbuminuria $(<20)$ & 78 & 65.0 \\
Microalbuminuria (20-199) & 42 & 35.0 \\
Mean \pm SD & \multicolumn{2}{c}{$22.9 \pm 3.1$} \\
Range (min, max) & \multicolumn{2}{c}{2,105}
\end{tabular}

Table 11 shows urine microalbumin of the study patients, it was observed that $42(35.0 \%)$ patients had microalbuminuria and $78(65.0 \%)$ had normoalbuminuria. The mean microalbumin level was found $22.9 \pm 3.1 \mathrm{mg} / \mathrm{dl}$ with range from 2-105 mg/dl.

Table III: Comparison between urine microalbumin level with age $(n=120)$

\begin{tabular}{|c|c|c|c|c|c|}
\hline \multirow[t]{3}{*}{ Age (in years) } & \multicolumn{4}{|c|}{ Urine microalbuminuria (mg/L) } & \multirow[t]{3}{*}{$p$ value } \\
\hline & \multicolumn{2}{|c|}{$\begin{array}{c}\text { Normo albuminuria } \\
(n=78)\end{array}$} & \multicolumn{2}{|c|}{$\begin{array}{c}\text { Microalbuminuria } \\
(n=42)\end{array}$} & \\
\hline & $\mathbf{n}$ & $\%$ & $\mathbf{n}$ & $\%$ & \\
\hline 30 & 4 & 5.1 & 8 & 19.0 & \\
\hline $31-40$ & 28 & 35.9 & 14 & 33.3 & \\
\hline $41-50$ & 38 & 48.7 & 18 & 42.9 & \\
\hline $51-60$ & 6 & 7.7 & 2 & 4.8 & \\
\hline$>60$ & 2 & 2.6 & 0 & 0.0 & \\
\hline Mean \pm SD & \multicolumn{2}{|c|}{$44.3 \pm 8.7$} & \multicolumn{2}{|c|}{$40.2 \pm 7.5$} & $0.076^{\mathrm{ns}}$ \\
\hline Range (min, $\max$ ) & \multicolumn{2}{|c|}{30,73} & \multicolumn{2}{|c|}{28,55} & \\
\hline
\end{tabular}

ns $=$ not significant

$p$ value reached from unpaired t-test

Table III shows comparison between age with urine microalbumin level. It was observed that in normoalbuminuria group, 38(48.7\%) patients were belonged to $41-50$ years and in microalbuminuria group, it was $18(42.9 \%)$ patients. The mean age was found $44.3 \pm 8.7$ years in normoalbuminuria group and $40.2 \pm 7.5$ years in normoalbuminuria group. The difference was statistically not significant $(p>0.05)$ between two group. 
Table IV: Comparison between urine microalbumin level with sex $(n=120)$

\begin{tabular}{|c|c|c|c|c|c|}
\hline \multirow[t]{3}{*}{ Sex } & \multicolumn{4}{|c|}{ Urine microalbumin level (mg/L) } & \multirow[t]{2}{*}{$p$ value } \\
\hline & \multicolumn{2}{|c|}{$\begin{array}{l}\text { Normoalbuminuria } \\
\qquad(n=78)\end{array}$} & \multicolumn{2}{|c|}{$\begin{array}{l}\text { Microalbuminuria } \\
\qquad(n=42)\end{array}$} & \\
\hline & $n$ & $\%$ & $\mathrm{n}$ & $\%$ & \\
\hline Male & 34 & 43.6 & 30 & 71.4 & $0.039^{\mathrm{s}}$ \\
\hline Female & 44 & 56.4 & 12 & 28.6 & \\
\hline
\end{tabular}

$\mathrm{s}=$ significant $p$ value reached from chi square t-test

Table V : Comparison between serum magnesium with urine microalbumin $(n=120)$

Serum magnesium $(\mathrm{mg} / \mathrm{dl})$ Urine microalbumin $(\mathrm{mg} / \mathrm{L}) \quad p$ value

\begin{tabular}{lccccc} 
& $\begin{array}{c}\text { Normoalbuminuria } \\
(\mathbf{n = 7 8 )}\end{array}$ & \multicolumn{2}{c}{$\begin{array}{c}\text { Microalbuminuria } \\
(\mathbf{n = 4 2})\end{array}$} \\
& $\mathrm{n}$ & $\%$ & $\mathrm{n}$ & $\%$ & \\
$<1.8$ (low) & 22 & 28.2 & 14 & 33.3 & \\
$1.8-2.4$ (normal) & 56 & 71.8 & 28 & 66.7 & \\
Mean \pm SD & \multicolumn{2}{c}{$2.2 \pm 0.3$} & & $1.9 \pm 0.2$ & $0.001^{\mathrm{s}}$ \\
Range (min, max) & \multicolumn{2}{c}{$1.5,2.4$} & & $1.5,2.2$ &
\end{tabular}

$\mathrm{S}=$ significant $p$ value reached from unpaired t-test

Table V shows comparison between serum magnesium level with urine microalbumin. It was observed that $22(28.2 \%)$ patients had low serum magnesium in normoalbuminuria group and $14(33.3 \%)$ in microalbuminuria group. The mean serum magnesium was found $2.2 \pm 0.3 \mathrm{mg} / \mathrm{dl}$ in normoalbuminuria and $1.9 \pm 0.2 \mathrm{mg} / \mathrm{dl}$ in microalbuminuria group. The difference was statistically significant $(p<0.05)$ between two groups.

\section{Discussion}

The cross sectional study was aimed at determining the serum magnesium concentration in newly detected diabetic population and correlating it with microalbumin level in urine. The findings of this study was compared with the results of some other published articles elsewhere in the world to verify the results. In this study, 120 patients of newly detected type 2 diabetes mellitus were included. It was observed that $36(30.0 \%)$ had $<1.8 \mathrm{mg} / \mathrm{dl}$ and $84(70 \%)$ had normal serum magnesium level $(1.8-2.4 \mathrm{mg} / \mathrm{dl})$ and the mean $\pm \mathrm{SD}$ for serum magnesium in study population was $1.92 \pm 0.3 \mathrm{mg} / \mathrm{dl}$. Shaikh M k et al. found that the mean \pm SD for serum magnesium in overall subjects was $1.34 \pm 0.53$. The hypomagnesemia was identified in 08 (14.5\%) patients of type 1 diabetes and 47 (85.5\%) of type 2 diabetes $(p=0.02)$. The hypomagnesemia was identified in patients with diabetes mellitus (type 1 and type 2) with statistical significant values. ${ }^{12}$ In another study done by Ferdousi $S$ et al. found that serum magnesium concentration in the type 2 diabetic patients was found significantly $(p<0.001)$ lower than that of control group. ${ }^{13}$ The reasons of decreased magnesium in type 2 diabetes mellitus might be due to higherurinary losses or impaired absorption of magnesium as compared to healthy persons. Urinary microalbumin level was measured in 120 subjects of newly detected type 2 diabetes mellitus.

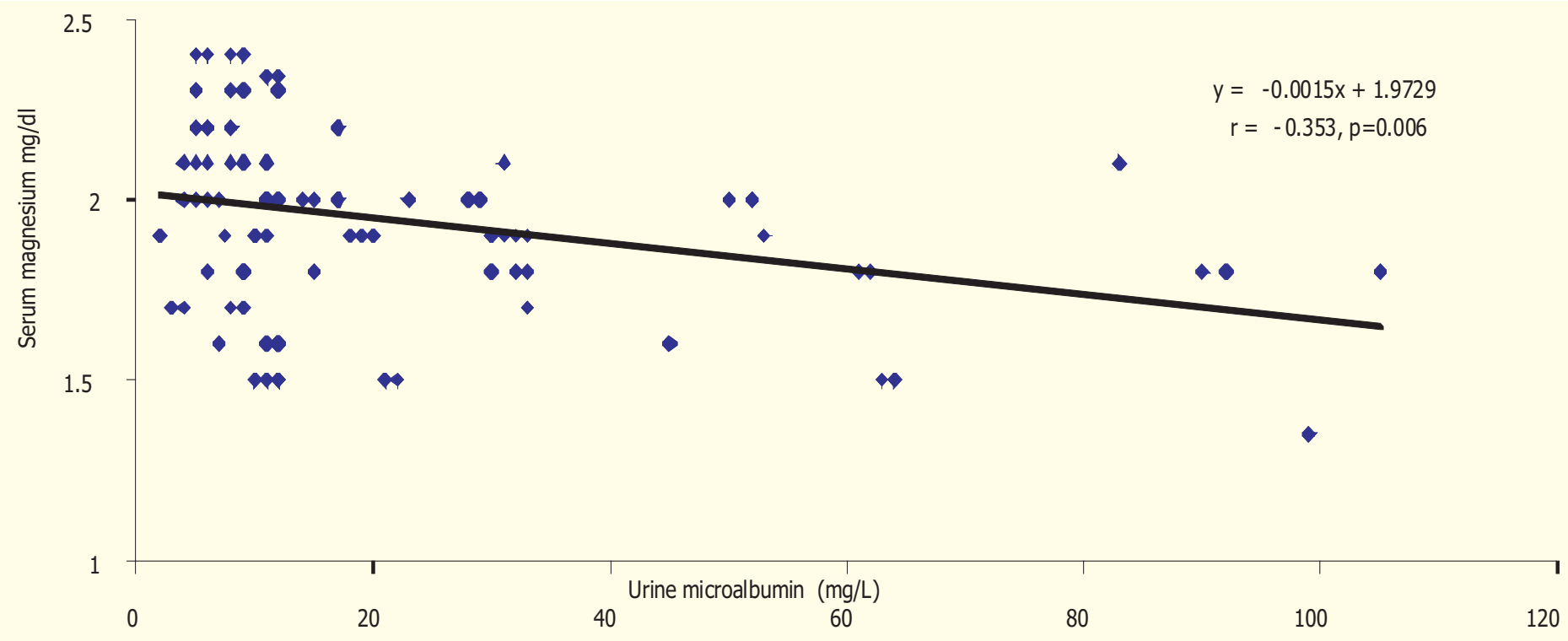

Figure 1: Scatter diagram shows correlation between urine microalbumin and serum magnesium $(n=120)$.

Figure 1 shows significant negative correlation ( $r=-0.353$; $p=0.006$ ) between urine microalbumin and serum magnesium level, the correlation was statistically significant $(p<0.05)$.
It was observed that $42(35.0 \%)$ patients had microalbuminuria and $78(65.0 \%)$ had normoalbuminuria. The mean microalbumin level was found $22.9 \pm 3.1 \mathrm{mg} / \mathrm{L}$ with range from 2-105 mg/L.Xu $B$ et al had shown that $11.37 \%$ of the study population had 
microalbuminuria. ${ }^{10}$ In another study done by Varghese et al.(2016) found that overall prevalence of microalbuminuria $36.3 \% .^{8}$

It was observed that in normoalbuminuria group, $48.7 \%$ patients were belonged to 41-50 years and in microalbuminuria group, it was $42.9 \%$. The mean age was found $44.3 \pm 8.7$ years in normoalbuminuria group and $40.2 \pm 7.5$ years in microalbuminuria group. The difference was statistically not significant $(p>0.05)$ between two groups. In a study done by Anesh $\mathrm{T}$ et al. found that the mean age of microalbuminuria group was $57.15 \pm 10.17$. This difference in result might be due to demographical variation. ${ }^{7}$

In present study, It was observed that majority of the patients $71.4 \%$ in microalbuminuria group were male and it is $43.6 \%$ in normoalbuminuria group. The difference was statistically significant $(p<0.05)$ between two group. In a study done by Anesh $T$ et al,2016 found that $63.8 \%$ microalbuminic patients were male. ${ }^{7}$ In another study, Rao P P et al. shown that about $66 \%$ were males and $34 \%$ were females in both group. ${ }^{3}$ Therefore this study was consistent with the previously published studies.

It was observed that $22(28.2 \%)$ patients had low serum magnesium in normoalbuminuria group and $14(33.3 \%)$ in microalbuminuria group. The mean serum magnesium was found $2.2 \pm 0.3 \mathrm{mg} / \mathrm{dl}$ in normoalbuminuria and $1.9 \pm 0.2 \mathrm{mg} / \mathrm{dl}$ in microalbuminuria group. The difference was statistically significant $(p<0.05)$ between two groups. In the present study, the mean serum $\mathrm{Mg}^{++}$levels in normoalbuminuria and microalbuminuria were $2.2 \pm 0.3(\mathrm{mg} / \mathrm{dl})$ and $1.9 \pm 0.2(\mathrm{mg} / \mathrm{dl})$, respectively. The results of present study was consistent with the studies done by Rao P P et al. and Anesh T et al. 3,7

The negative correlation $(r=-.353)$ between serum magnesium level and urinary microalbumin level in newly detected type 2 diabetes mellitus patients was statistically significant $(P<0.05)$. In a study conducted by Anesh $\mathrm{T}$ et al. found statistically significant correlation $(p<0.001)$ between serum magnesium and urine microalbumin. ${ }^{7}$ Sakaguchi $Y$ et al., (2012) also found statistically significant correlation $(p=0.004)$ between these two parameters in diabetic patients. ${ }^{1}$

\section{Conclusion}

Patients with low serum magnesium levels at diagnosis of diabetes mellitus are associated with chances of microalbuminuria. Therefore, hypomagnesemia should be treated as a risk factor in developing microalbuminuria in early diabetes mellitus cases.

\section{References}

1. Sakaguchi Y, Shoji T, Hayashi T, Suzuki A, Kawabata H, Niihata k, Okada N, Isaka Y, Rakugi H, Tsubakihara Y, 'Hypomagnesemia in type 2 diabetic nephropathy: a novel predictor of endstagerenal disease'. Diabetes Care,2012;35; 1591-1597.

2. Puri M, Gujral U, Nayyar S B, 'Comparative study of serum zinc, magnesium and copper levels among patients of type 2 diabetes mellitus with and without microangiopathic complications' Innovative Journal of Medical and Health Science,2013; 3(6); 274 - 278.

3. Rao P P, Shariff M G, 'Serum magnesium levels in type 2 diabetic patients with microalbuminuria and normoalbuminuria'. International Journal of Scientific Study,2015;3(4);11-15.

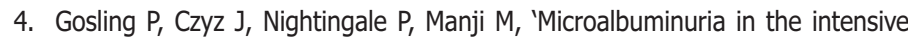
care unit: Clinical correlates and association with outcomes in 431 patients'. Crit Care Med , 2006;34; 2158-2166.

5. Gross J L, Deazevedo M J, Silveiro S, Henriquecanani L, 'Diabetic Nephropathy: Diagnosis, Prevention, and Treatment'. Diabetes Care, 2005;28; 178-188.

6. Barbagallo $M$, Dominguez L J, 'Magnesium and Type 2 Diabetes: An Update'.Int J Diabetes Clin Res,2015; 2(19); 2377-3634.

7. Aneesh $T$, Rao $M Y$, 'Serum magnesium in type 2 diabetic patients with microalbuminuria and overt proteinuria'. IOSR Journal of Dental and Medical Sciences (IOSR-JDMS),2016;15(1);30-35.

8. Shao N, Kuang HY, Wang N, Gao X Y, Hao M, Zou W''Relationship between oxidant/antioxidant markers and severity of microalbuminuria in the early stage of nephropathy in type 2 diabetic patients.' J Diabetes Res, 2013; Article ID 232404.

9. Kundu D Roy, Mandal T, Bandyopadhyay U, Ghosh E, 'Relation of microalbuminuria to glycosylated hemoglobin and duration of type 2 diabetes' Nigerian Journal of Clinical Practice,2013; 16(2);216-220.

10. Xu B, Sun J, Deng $X$, Huang $X$, Sun W, Xu Y, Xu M, Lu, 'Low Serum Magnesium Level Is Associated with Microalbuminuria in Chinese Diabetic Patients.'International Journal of Endocrinology , 2013; Article ID 580685;16.

11. Hamed S R, Pavkovic P, Metelko Z, 'Microalbuminuria and Diabetes Mellitus' DiabetologiaCroatica,2002; 31(4); 209-221.

12. Shaikh M K, Devrajani B R, Soomro A A,'Hypomagnesemia in Patients with Diabetes mellitus.'World Appl. Sci. J.,2011;12 (10);1803-1806.

13. Ferdousi S, Mollah F H, Mia M, 'Serum Levels of Zinc and Magnesium in Newly Diagnosed Type-2 Diabetic Subjects.'Bangladesh J Med Biochem.,2010; 3(2);46-49. 